\title{
Chlorhexidine inhibits L1 cell adhesion molecule-mediated neurite outgrowth in vitro
}

\author{
Aaron M. Milstone ${ }^{1}$, Penny Bamford ${ }^{2}$, Susan W. Aucott ${ }^{1}$, Ningfeng Tang ${ }^{2}$, Kimberly R. White ${ }^{2}$ and Cynthia F. Bearer ${ }^{2}$
}

BACKGROUND: Chlorhexidine is a skin disinfectant that reduces skin and mucous membrane bacterial colonization and inhibits organism growth. Despite numerous studies assessing chlorhexidine safety in term infants, residual concerns have limited its use in hospitalized neonates, especially low-birth-weight preterm infants. The aim of this study was to assess the potential neurotoxicity of chlorhexidine on the developing central nervous system using a well-established in vitro model of neurite outgrowth that includes laminin and L1 cell adhesion molecule (L1) as neurite outgrowth-promoting substrates.

METHODS: Cerebellar granule neurons are plated on poly L-lysine, L1, or laminin. Chlorhexidine, hexachlorophene, or their excipients are added to the media. Neurons are grown for $24 \mathrm{~h}$, fixed, and neurite length is measured.

RESULTS: Chlorhexidine significantly reduced the length of neurites grown on L1 but not on laminin. Chlorhexidine concentrations as low as $125 \mathrm{ng} / \mathrm{ml}$ statistically significantly reduced neurite length on L1. Hexachlorophene did not affect neurite length.

CONCLUSION: Chlorhexidine at concentrations detected in the blood following topical applications in preterm infants specifically inhibited L1-mediated neurite outgrowth of cerebellar granule neurons. It is now vital to determine whether the bloodbrain barrier is permeable to chlorhexidine in preterm infants.

$C^{\mathrm{h}}$ hlorhexidine is a skin disinfectant that reduces skin and mucous membrane bacterial colonization and inhibits organism growth. It is frequently used to prevent infections and the spread of antibiotic-resistant bacteria, such as methicillin-resistant Staphylococcus aureus $(1,2)$. Chlorhexidine is used to prepare the skin before surgical procedures and reduces the risk of surgical site infections (3). The Centers for Disease Control and Prevention recommend cleaning the skin with chlorhexidine before the placement of central venous catheters, because numerous studies have demonstrated reduced catheter infection rates following chlorhexidine skin preparation as compared with alternatives such as povidone-iodine. However, "no recommendation can be made for the safety or efficacy of chlorhexidine in infants aged $<2$ mo" (4).
Trace amounts of chlorhexidine can be absorbed through the skin after a single bath in adults and term neonates. In 1976, Case (5) showed that, in adults, chlorhexidine "is absorbed through intact human skin to an extraordinarily small degree, if at all." This report only detected chlorhexidine in feces of adults following a hand wash with $5 \%$ chlorhexidine digluconate. No chlorhexidine was detected in blood, indicating minimal absorption. In term neonates, given a 1 or $2 \%$ chlorhexidine bath, chlorhexidine was detected in 4 out of 20 neonates (range: $13.5-26.7 \mathrm{ng} / \mathrm{ml}$ ) (6). However, the interval between the bath and blood sampling was not reported, nor is it known when the chlorhexidine concentration may peak in the blood after topical exposure. There are no reports of immediate adverse consequences as a result of chlorhexidine absorption in studies of term newborns or adults, no data to suggest that detectable serum concentrations have clinical importance (7), and no data that chlorhexidine can cross the blood-brain barrier. Another broad-spectrum organopolychlorinated antiseptic, hexachlorophene (HEX), was found to penetrate intact human skin and cause vacuolar encephalopathy in newborns in the 1970s $(8,9)$, thus showing that antiseptics used without harm in adults can cause devastating neurological injury in infants. As a result, chlorhexidine has been scrutinized for its potential to be absorbed through the skin. Despite numerous studies assessing short-term outcomes from the use of chlorhexidine in term infants, residual concerns have limited its use in hospitalized neonates, especially in low-birth-weight preterm infants (10). No developmental neurotoxicity studies have been performed to assess the safety of chlorhexidine exposure in term or preterm neonates.

Our goal is to begin studies on the impact of chlorhexidine exposure on the developing central nervous system. In the current study, our objective was to assess the potential neurotoxicity of chlorhexidine using a well-established in vitro model of neurite outgrowth $(11,12)$ that includes both laminin and L1 cell adhesion molecule (L1) as outgrowth-promoting substrates. L1-mediated, but not laminin-mediated, neurite outgrowth is dependent on lipid rafts, portions of the plasma membrane similar to bacterial membranes disrupted by chlorhexidine (13). Thus, L1-mediated neurite outgrowth may be a sensitive indicator of chlorhexidine neurotoxicity. 
HEX has been shown to cause axonopathy in vitro. Although chemically distinct, both chlorhexidine and HEX contain the lipophilic moieties of polychlorinated phenol rings, making them both lipophilic. Measurement of neurite outgrowth may be one way to demonstrate the potential neurotoxicity of chlorhexidine and HEX (14).

Due to concerns that chlorhexidine may cause neurotoxicity to third-trimester equivalent preterm infants, cerebellar granule neurons (CGNs) are an ideal in vitro model, as neurite outgrowth of these neurons occurs at this age of development. Neurite outgrowth is a sensitive measure for nonlethal neurotoxicity and provides an excellent model to assess the potential cellular toxicity of chlorhexidine $(11,12)$. Neurite outgrowth occurs through different mechanisms depending on environmental cues. These cues include proteins either on the surface of other cells or in the extracellular matrix. L1 is one such environmental cue. It binds homophilically to itself, initiating the processes of protein trafficking, phosphorylation/dephosphorylation, and signal transduction in the growth cone. Laminin promotes neurite outgrowth by binding to the integrin receptor and hence represents a different mechanism by which neurite outgrowth is promoted. Together, these cell lines provide an opportunity to investigate the potential neurotoxicity of chlorhexidine.

\section{RESULTS}

We first tested whether chlorhexidine gluconate $((\mathrm{CHG})$ in a proprietary vehicle $(\mathrm{V}))$ inhibited L1-mediated neurite outgrowth by plating CGNs on a substrate of L1 (Figures 1 and
2). Ethanol was used as a positive control for inhibition of L1-mediated neurite outgrowth. We chose the highest concentration of chlorhexidine detected in the serum of a newborn following topical exposure $(1,021 \mathrm{ng} / \mathrm{ml})(15)$. As can be seen in Figures 1 and 2, compared with L1 control, CHG reduced neurite length of CGNs plated on L1 $(P<0.05)$. The vehicle $(\mathrm{V})$ in which CHG is solubilized had no effect on neurite length. There was no apparent effect on neurite branching under any of these conditions.

To determine whether these reagents reduce cell viability, we counted the number of cells per high-powered field. Nonviable cells lose adhesion and lift off the plates. Thus, decreasing number of adherent cells would indicate increased cell death. There was no difference in the number of cells adherent to the plate as compared with poly L-Lysine (PLL), and no difference was found between the number of cells adherent to the plate in $\mathrm{V}$ alone or $\mathrm{V}$ with $\mathrm{CHG}$ (Figure 3).

HEX is a known developmental neurotoxicant $(8,9,16)$. The ability of HEX to inhibit L1-mediated neurite outgrowth was tested. The concentration of HEX used was $100 \times$ that in the serum of a newborn with liver disease $(4,350 \mathrm{ng} / \mathrm{ml})(17)$. We found no significant effect of either dimethyl sulfoxide (DMSO) alone or DMSO with $1 \mathrm{mmol} / \mathrm{l} \mathrm{HEX}$ on L1-mediated neurite outgrowth (Figure 4).

To determine whether the inhibition of neurite outgrowth by CHG is specific to L1 or is a general effect on neurite outgrowth, we plated CGNs on laminin. Laminin is another cell adhesion molecule that binds to integrin receptors. As can be seen in Figure 5, neither the vehicles nor CHG or HEX
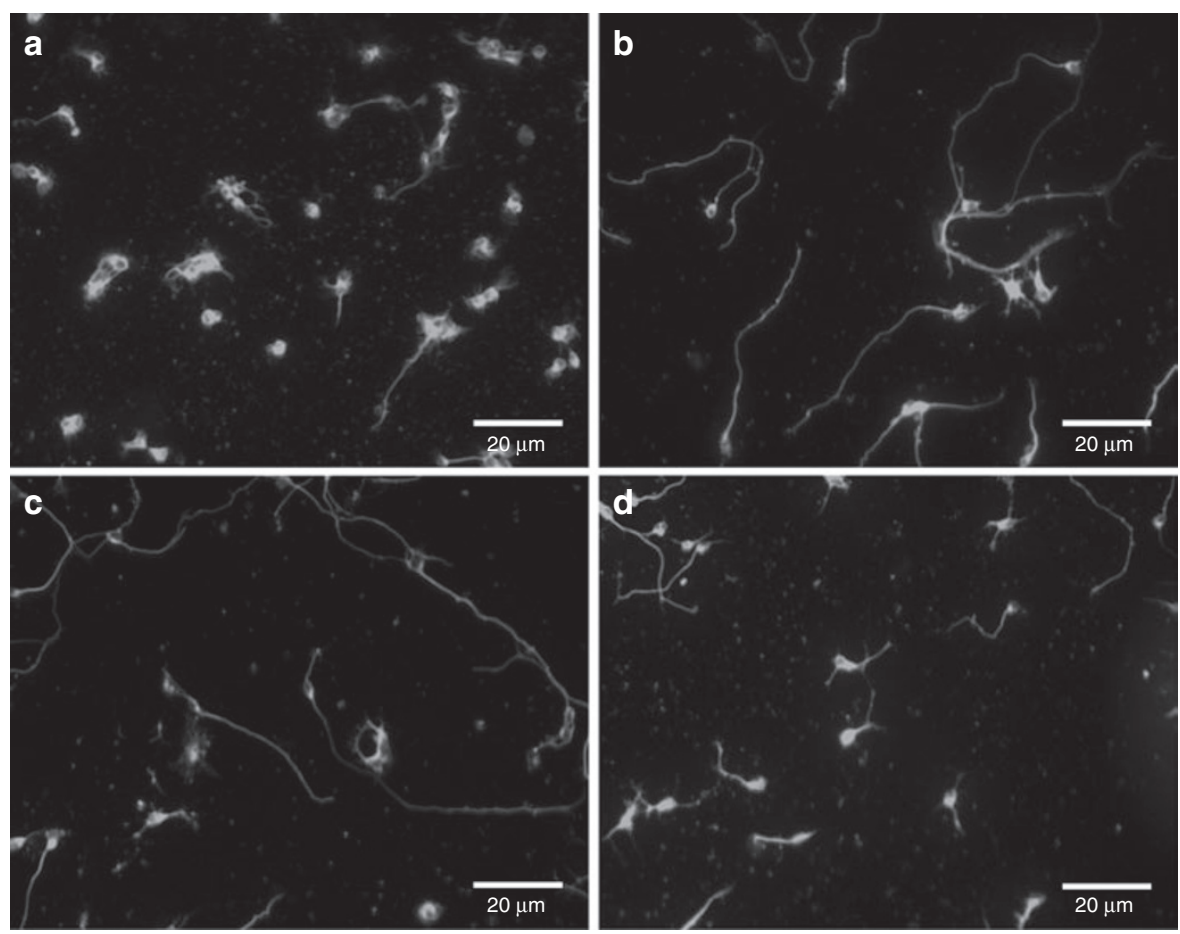

Figure 1. Chlorhexidine inhibits L1-mediated neurite outgrowth. Cerebellar granule neurons are plated on either poly L-lysine (PLL) alone or PLL plus L1-FC (L1), and then, ethanol (E, final concentration: $25 \mathrm{mmol} / \mathrm{l})$, chlorhexidine vehicle (V, final concentration: 1\%), or chlorhexidine in vehicle (CHG, final concentration: $1.0 \mu \mathrm{g} / \mathrm{ml} \mathrm{CHG}, 1 \%$ vehicle) are added to the media. The cells are grown for $24 \mathrm{~h}$, fixed, and immunostained. Representative photomicrographs are shown: (a) PLL alone; (b) L1; (c) L1 + V; and (d) L1 + V + CHG. Original magnification: $\times 20$. 


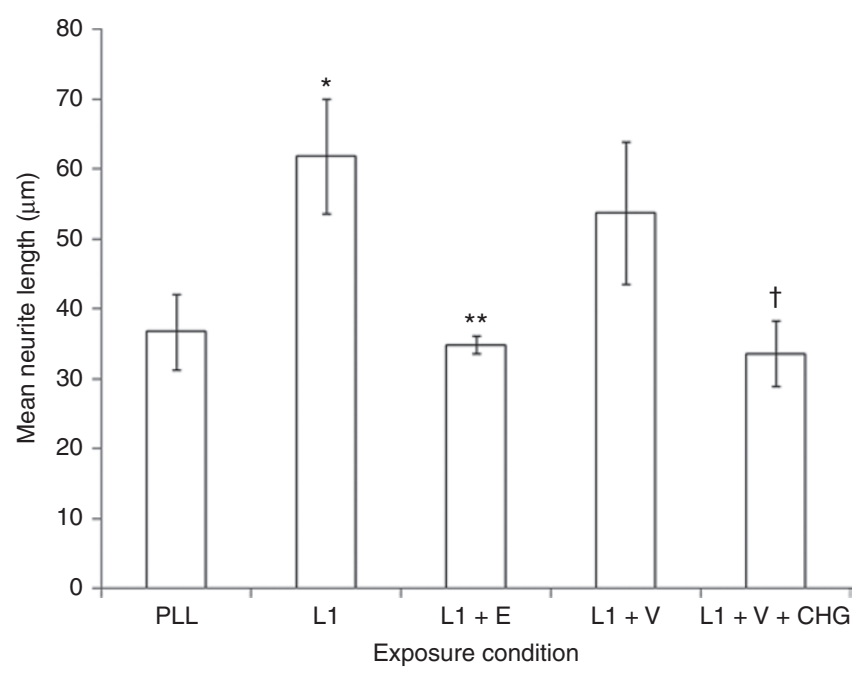

Figure 2. Chlorhexidine inhibits L1-mediated neurite outgrowth. Cerebellar granule neurons are plated on either poly L-lysine (PLL) alone or PLL plus L1-Fc (L1), and then, ethanol (E, final concentration: $25 \mathrm{mmol} / \mathrm{l})$, chlorhexidine vehicle ( $\mathrm{V}$, final concentration: 1\%), or chlorhexidine in vehicle (CHG, final concentration: $1.0 \mu \mathrm{g} / \mathrm{ml} \mathrm{CHG}, 1 \%$ vehicle) are added to the media. The cells are grown for $24 \mathrm{~h}$, fixed, and neurite length is measured. The mean of the neurite lengths for each condition is calculated, and then, the mean $\pm S D$ is determined for four separate experiments. ${ }^{P} P<$ 0.001 , PLL vs. L1; ${ }^{* *} P<0.01, \mathrm{~L} 1$ vs. $\mathrm{L} 1+\mathrm{E}$; and ${ }^{+} P<0.05, \mathrm{~L} 1+\mathrm{V}$ vs. $\mathrm{L} 1+\mathrm{V}+$ CHG. The $P$ value of $\mathrm{L} 1$ vs. $\mathrm{L} 1+\mathrm{V}$ is not significant (i.e., $P=0.29$ ).

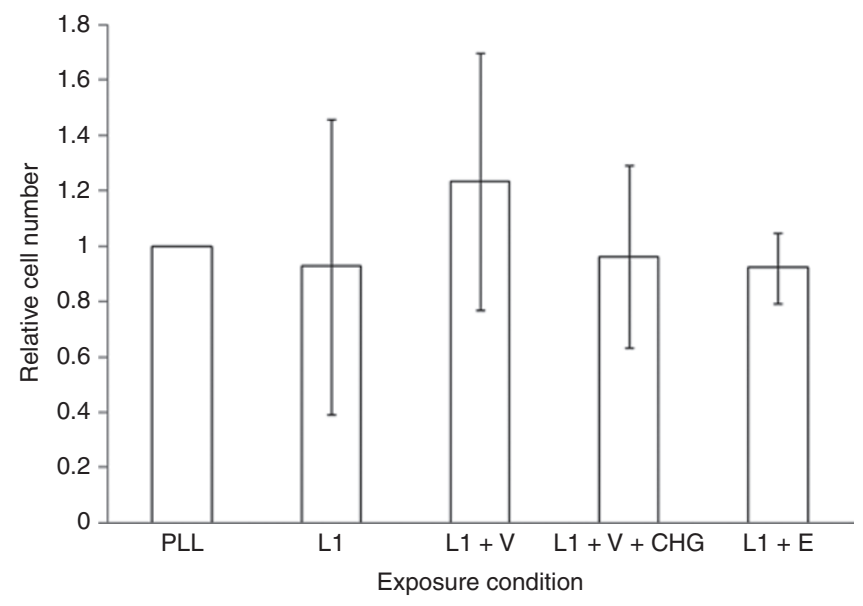

Figure 3. Chlorhexidine at $1.0 \mu \mathrm{g} / \mathrm{ml}$ does not increase cell death at $24 \mathrm{~h}$. Photomicrographs used to determine neurite length in Figure 2 were reexamined to determine the number of cells per high-powered field. Dead cells detach from the plate; therefore, a decrease in cell number as compared with poly L-lysine (PLL) alone would indicate increased cell death. The average number of cells in each photomicrograph obtained for each condition was determined and averaged for total cell number per high-powered field and divided by average cell number per high-powered field in PLL alone to obtain a relative cell number. Four separate experiments were counted, and the average relative cell number $\pm \mathrm{SD}$ is shown. No significant change in cell number compared with PLL alone was determined. CHG, chlorhexidine; E, ethanol; $\mathrm{V}$, vehicle.

had any effect on the length of neurites of CGNs grown on laminin.

To determine the concentrations at which CHG is capable of inhibiting L1-mediated neurite outgrowth, we examined the impact of CHG concentration on neurite length. The results from four experiments are shown in Figure 6. Vehicle alone did

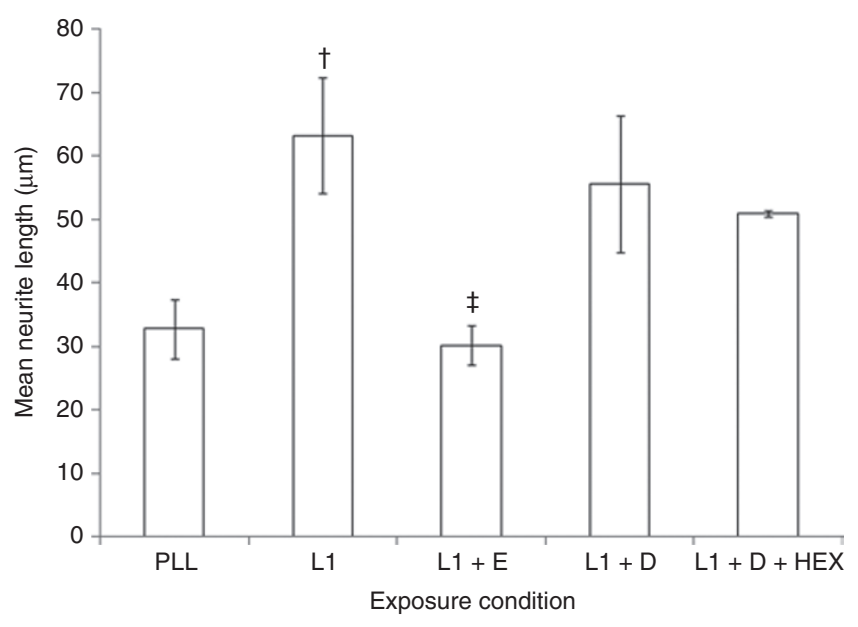

Figure 4. Hexachlorophene does not inhibit L1-mediated neurite outgrowth. Cerebellar granule neurons are prepared as in Figure 1. Additions to the media are $25 \mathrm{mmol} / \mathrm{l}$ ethanol $(\mathrm{L} 1+\mathrm{E}), 1 \%$ dimethyl sulfoxide (DMSO) (L1 + D), or $1 \%$ DMSO with $1 \mathrm{mmol} / \mathrm{l}$ hexachlorophene (L1 + D $+\mathrm{HEX})$. The mean of the neurite lengths for each condition is calculated, and then, the mean $\pm \mathrm{SD}$ is determined for four separate experiments. ${ }^{\dagger} P<$ 0.05 , poly L-lysine (PLL) vs. L1; ${ }^{\ddagger} P<0.02, \mathrm{~L} 1$ vs. $\mathrm{L} 1+\mathrm{E}$. The $P$ values of $\mathrm{L} 1 \mathrm{vs.}$ $L 1+D$ and $L 1+D$ vs. L1 + D + HEX are not significant.

not have a significant effect on L1-mediated neurite outgrowth. CHG at a concentration of $31 \mathrm{ng} / \mathrm{ml}$ did not inhibit neurite outgrowth in cultures with $\mathrm{L} 1$ and $\mathrm{V}$ alone. However, $62 \mathrm{ng} / \mathrm{ml}$ of CHG showed a trend of reduced neurite length $(P=0.08)$. CHG concentrations of $\geq 125 \mathrm{ng} / \mathrm{ml}$ significantly inhibited neurite growth similar to ethanol, the positive control. There is no significant difference in neurite length of CGNs grown in 62, $125,250,500$, or $1,000 \mathrm{ng} / \mathrm{ml}$ of CHG and PLL.

\section{DISCUSSION}

The recent demonstration that chlorhexidine is systemically absorbed and can be detected in the blood of preterm infants days after exposure (18) raises concerns about the possible consequences of exposure in preterm infants. To begin to determine if chlorhexidine concentrations detected in preterm infants are capable of causing developmental neurotoxicity, we examined the effects of similar concentrations on neurite outgrowth. The model of neurite outgrowth reported here is dependent on lipid rafts, microdomains of the plasma membrane which may be susceptible to the chemical properties of chlorhexidine that provide bactericidal activity.

Our results suggest that chlorhexidine at concentrations observed in the blood of preterm infants (18) specifically inhibited L1-mediated neurite outgrowth of cerebellar granule neurons. The effect of chlorhexidine is found to be specific to neurite outgrowth of neurons plated on L1. It is interesting to speculate on the differences in susceptibility of laminin-mediated neurite outgrowth vs. that of L1-mediated neurite outgrowth. L1-mediated neurite outgrowth is dependent on lipid rafts, whereas laminin-mediated neurite outgrowth is not (19). Lipid rafts are microdomains of the plasma membrane that are important for protein-protein interaction and signal transduction. Disruption of the lipid raft by photobleaching (19) or 


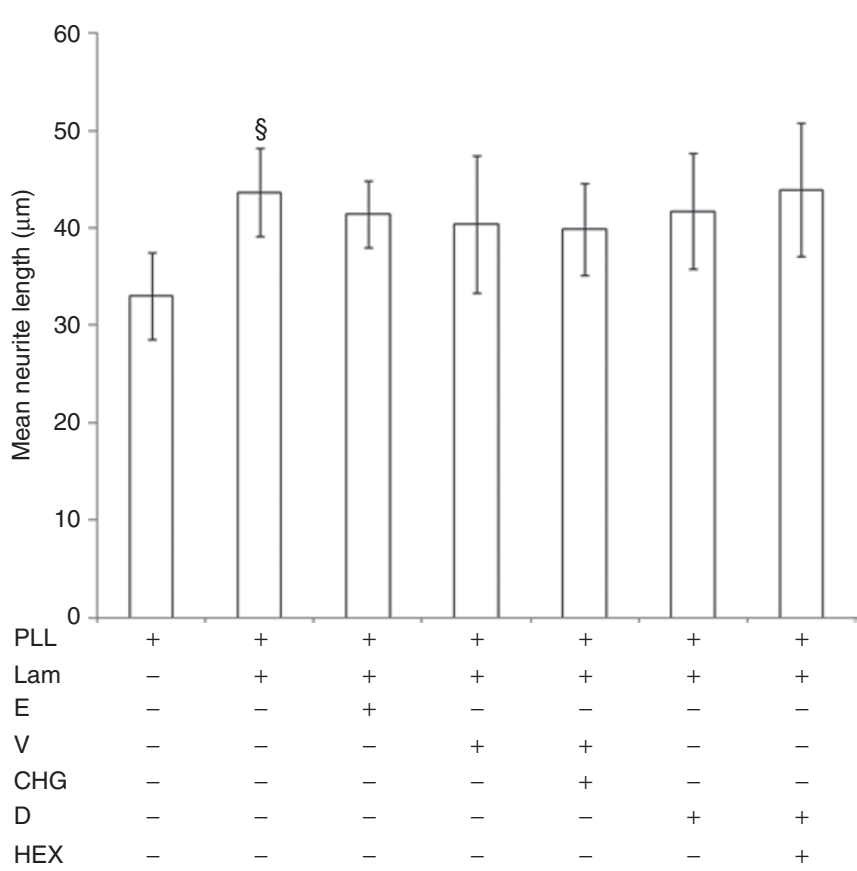

Figure 5. Neither chlorhexidine nor hexachlorophene inhibit lamininmediated neurite outgrowth. Cerebellar granule neurons are plated on either poly L-lysine (PLL) alone or PLL plus laminin (Lam). The following are added to the media to give final concentrations of: ethanol $(E, 25 \mathrm{mmol} / \mathrm{l})$, chlorhexidine vehicle ( $\mathrm{V}, 1 \%)$, chlorhexidine $(\mathrm{CHG}, 1.0 \mu \mathrm{g} / \mathrm{ml})$, DMSO (D, $1 \%)$, or hexachlorophene (HEX, $1 \mathrm{mmol} / \mathrm{l})$. Neurite length is determined as described in Figure 2 . The mean of the neurite lengths for each condition is calculated, and then, the mean $\pm S D$ is determined for four separate experiments. ${ }^{5} P<0.005$, PLL vs. Lam.

cholesterol chelation (20) reduces neurite outgrowth of neurons plated on L1 but not laminin. The developmental neurotoxicant ethanol has been shown to disrupt lipid raft function (20-25). Recently, data show that chlorhexidine's bactericidal action occurs through effects on the plasma membrane (13). Using model membranes of 1,2 dimyristroyl-sn-glycero-3-phosphocholine and neutron diffraction, chlorhexidine is shown to insert itself into the lipid bilayer with the phenols stacked forming a wedge, and the hexamethylene linker interaction with the headgroup, allowing cytoplasmic elements to leak out. Of note, chlorhexidine is only active on viruses possessing lipid envelopes. We speculate that a sensitive function of the plasma membrane in growth cones is the dynamic nature of lipid rafts. A perturbation of the plasma membrane may impede the trafficking of critical proteins, such as L1, through the lipid raft. Further studies are needed to explore this potential mechanism.

The present study confirms findings from previous studies investigating the cytotoxic effect of chlorhexidine in vitro. Because chlorhexidine is frequently used for oral care to prevent dental plaque and gingivitis, many studies have examined and identified in vitro toxicity of chlorhexidine after direct application on gingival epithelial cells, odontoblast-like cells, and periodontal ligament cells (26-29). Similar cytotoxicity has been seen with HeLa cells and human newborn fibroblasts (30). These studies have focused on chlorhexidine concentrations used in topical preparations. A recent study exposed

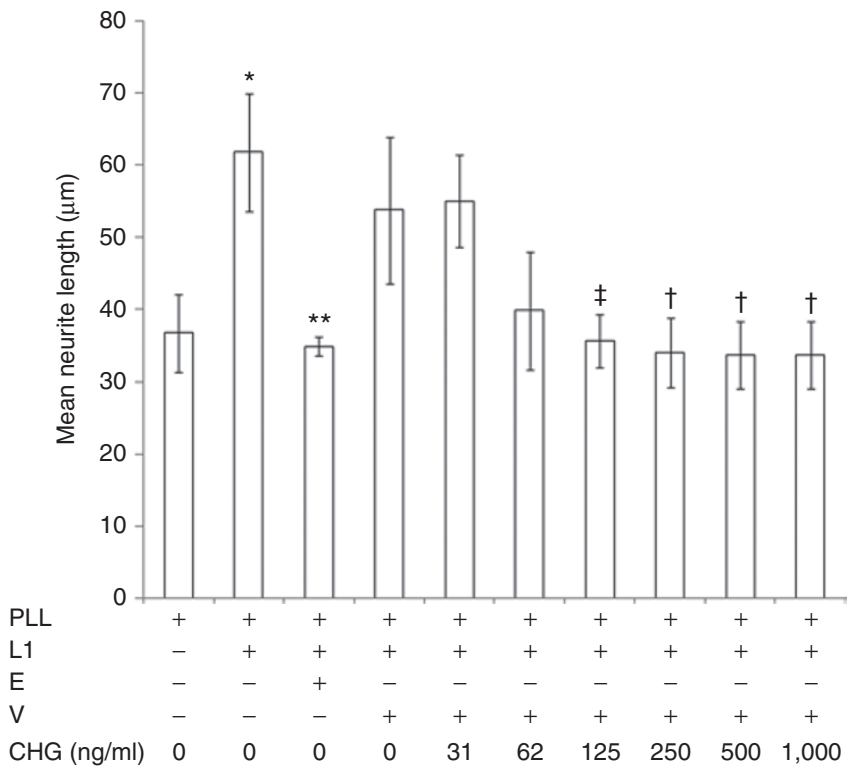

Figure 6. Chlorhexidine inhibits L1-mediated neurite outgrowth at pharmacologic concentrations. Cerebellar granule neurons are prepared as described in Figure 1 and plated on poly L-lysine alone (PLL) or with L1 (L1). Additions to the media are as follows: ethanol, E ( $25 \mathrm{mmol} / \mathrm{l})$; chlorhexidine vehicle, V (1\%); and increasing concentrations of chlorhexidine $(\mathrm{CHG})$ as indicated. Mean neurite lengths from four separate experiments are calculated, and then the mean $\pm S D$ are calculated. ${ }^{*} P<0.001$, PLL vs. $\mathrm{L} 1 ;{ }^{* *} P<0.01, \mathrm{~L} 1$ vs. $\mathrm{L} 1+\mathrm{E} ;{ }^{\ddagger} P<0.02, \mathrm{~L} 1+\mathrm{V}$ vs. $\mathrm{L} 1+\mathrm{V}+\mathrm{CHG}$ at 125 $\mu \mathrm{g} / \mathrm{ml} ;{ }^{+} P<0.05, \mathrm{~L} 1+\mathrm{V}$ vs. L1 + V + CHG at 250, 500, and 1,000 $\mu \mathrm{g} / \mathrm{ml}$.

human-derived neuroblastoma cells and rat Schwann cells to diluted chlorhexidine (20\% stock solution with a density of $1.06 \mathrm{~g} / \mathrm{ml}$ diluted to a lowest concentration of $1: 2,000$ or 500 $\mu \mathrm{g} / \mathrm{ml}$ ) and found evidence of cytotoxicity (31). The chlorhexidine concentrations used in that study $(500 \mu \mathrm{g} / \mathrm{ml})$ were much higher than those reported in human serum following topical exposure and those used in the present study.

This study also demonstrates that chlorhexidine and HEX have different toxic effects on neurite outgrowth. In vivo studies have found differences in the toxic effects of chlorhexidine and HEX. Studies in baboons have found that daily topical HEX application induced changes in myelin (32). Studies in macaques found that daily chlorhexidine bathing did not produce any histopathological changes in the brain following $90 \mathrm{~d}$ of exposure (33). However, chlorhexidine was undetectable in the blood of these monkeys, so no chlorhexidine could have possibly gained access to the brain. There are no studies assessing whether chlorhexidine can cross the blood-brain barrier. Overall, many studies demonstrate that chlorhexidine can cause cytotoxicity, but the clinical correlation of these in vitro studies remains unknown. Specifically for our study, it is not known if chlorhexidine in the blood can cross the blood-brain barrier and cause direct exposure to neurons.

The primary limitations of this study include the uncertainty of extrapolating media concentrations of chlorhexidine and HEX to blood concentrations of exposed premature infants. The permeability of the blood-brain barrier in premature infants is affected by many factors, including developmental maturation and disruption caused by disease (34-36). Thus, the local concentration of chlorhexidine next to neuronal 
membranes in humans is unknown. More research is needed in this area. A secondary limitation is the relationship between inhibition of neurite outgrowth and clinical neurodevelopmental effects. More research is needed linking the behavior to chlorhexidine exposure. This study provides rationale for examining behavior known to be disrupted in L1 knockout animals, such as cage activity, rotarod, open-field test, social exploration, and Morris water maze (37).

In summary, chlorhexidine at concentrations reported following topical applications in infants specifically inhibited L1-mediated neurite outgrowth of cerebellar granule neurons. Chlorhexidine has lifesaving applications for neonates around the world, including umbilical cord care to reduce neonatal mortality (38). As chlorhexidine use increases in hospitalized patients, further studies are needed to determine the clinical relevance of these in vitro findings. It is now vital to determine whether the bloodbrain barrier is permeable to chlorhexidine in premature infants.

\section{METHODS}

\section{Antibodies and Materials}

Antibodies used in this research are mouse monoclonal anti- $\beta$ III tubulin obtained from Sigma (St. Louis, MO)and goat antimouse IgG (heavy and light chain) conjugated to Alexa 488, which is obtained from Invitrogen (Grand Island, NY). The substrates used for these experiments are $0.1 \%$ PLL (Sigma), laminin (Invitrogen, Carlsbad, $\mathrm{CA}$ ), and L1-Fc, a chimeric protein consisting of the extracellular domain of L1 cell adhesion molecule and the Fc domain of IgG, which is purchased from R\&D system (Minneapolis, MN). CHG and V alone are supplied by Sage Products (Carey, IL). Cells are viewed on a Zeiss Observer Z1 fluorescence inverted microscope (Carl Zeiss Microscopy, Oberkochen, Germany). Images are captured using Axiovision camera software (Carl Zeiss), and neurite outgrowth is measured using Image J software (National Institutes of Health, Bethesda, MD).

\section{Preparation of Coverslips}

Coverslips obtained from Fisher Scientific (Hanover Park, IL) are cleaned and placed in the bottom of each of a 24-well Costar tissue culture flat bottom plate. One $\mathrm{ml}$ ice-cold $0.1 \%$ PLL is placed into each of the 24 wells. They are then sealed and placed in the refrigerator at $4{ }^{\circ} \mathrm{C}$ overnight. Laminin-containing wells are prepared as follows: the PLL is removed from the wells, each well is washed three times with ice-cold phosphate-buffered saline (PBS), then $1 \mathrm{ml}$ of a $2 \mathrm{mg} / \mathrm{ml}$ laminin solution in PBS is added to each well. The plate is again sealed and placed in the refrigerator overnight at $4{ }^{\circ} \mathrm{C}$. L1-containing wells are prepared as follows: just before the addition of CGNs, the PLL is removed from the wells, and each well is washed three times with ice-cold PBS. CGNs are added to the well in a final volume of $1 \mathrm{ml}$. L1-Fc, a chimeric protein consisting of the extracellular domain of L1 and the Fc domain of IgG, is added following CGNs to give a final concentration of $0.2 \mu \mathrm{g} / \mathrm{ml}$.

\section{Cell Cultures}

CGNs from 6-day-old Sprague-Dawley rat pups are prepared as previously described $(11,20)$. To minimize pain and discomfort, the pups are rapidly decapitated as approved by the University of Maryland School of Medicine Institutional Animal Care and Use Committee. Viability of CGNs is assessed with trypan blue and is routinely $>90 \%$. CGNs are plated on prepared glass coverslips coated with PLL, laminin, or L1-Fc in Neurobasal media (Gibco, Rockville, MD) with the following additions: 2\% B27 supplement (Gibco), $20 \mathrm{mmol} / \mathrm{l}$ L-glutamine, $6 \mathrm{~g} / \mathrm{l}$ glucose, $20 \mathrm{mmol} / \mathrm{l} \mathrm{N}$-2-hydroxyethylpiperazineN9-2-ethanesufonic acid and penicillin/streptomycin (pH 7.2). CGN cultures are incubated for $2 \mathrm{~h}$ at $37^{\circ} \mathrm{C}$ in $10 \% \mathrm{CO}_{2}$ to allow for cell adhesion. Ten microliter aliquots of DMSO (final concentration: 1\%) or DMSO with $40.7 \mathrm{mg} / \mathrm{ml}(100 \mathrm{mmol} / \mathrm{l}) \mathrm{HEX}$ or the vehicle for CHG (V) either alone $(1 \% \mathrm{~V})$ or containing $100 \mu \mathrm{g} / \mathrm{ml} \mathrm{CHG}$ are added to $1 \mathrm{ml}$ of CGN cultures to give a final concentration of $407 \mu \mathrm{g} / \mathrm{ml}(1$ $\mathrm{mmol} / \mathrm{l}) \mathrm{HEX}$ or $1.0 \mu \mathrm{g} / \mathrm{ml}(0.002 \mathrm{mmol} / \mathrm{l}) \mathrm{CHG}$. For the CHG dilution curve, the stock solution is serially diluted in vehicle $1: 2$. Aliquots of $10 \mu \mathrm{l}$ of the stock and each dilution are added to the wells. Cells are grown for $24 \mathrm{~h}$ in a humid atmosphere of $90 \%$ air and $10 \% \mathrm{CO}$ at $37^{\circ} \mathrm{C}$. After $24 \mathrm{~h}$, the media is removed, and cells are washed three times with ice-cold PBS. The cells are then fixed in $4 \%$ paraformaldehyde for $30 \mathrm{~min}$ at room temperature, followed by three more washes with PBS. Blocking solution (3\% bovine serum albumin/0.2\% Triton $\mathrm{X}-100 / \mathrm{PBS}$ ) is added to each coverslip for $1 \mathrm{~h}$ at $37^{\circ} \mathrm{C}$, or overnight at $4{ }^{\circ} \mathrm{C}$. After blocking, cells are immunostained.

\section{Immunostaining}

Blocked cells are exposed to mouse monoclonal anti-tubulin- $\beta$ III for $1 \mathrm{~h}$ at $37^{\circ} \mathrm{C}$ and washed three times with PBS and further exposed to Alexa 488 antimouse $\operatorname{IgG}$ for $1 \mathrm{~h}$ at $37^{\circ} \mathrm{C}$, washed three times with PBS, and then mounted on glass slides.

\section{Neurite Outgrowth}

Eligible neurites are identified by a masked investigator in an a priori design. The eligible neurons are photographed, and neurite length was measured. Only neurons containing neurites that meet the following criteria are measured: (i) the neurite is as long as the width of soma; (ii) the neurite is not synapsing on another neuron; and (iii) the neuron must be single and not in a cluster (11). Images of neurites are measured using Image J (NIH). At least 30 neurites from each coverslip are measured.

\section{Cell Death}

All photomicrographs from each condition were counted for cell bodies present. The number of cell bodies per high-powered field was averaged. Each value was divided by average cell number per highpowered field for PLL alone to give a relative cell number. The relative cell number was averaged across four experiments.

\section{Statistical Analysis}

The mean neurite length is determined for each condition from each cell preparation. The mean neurite length for each cell preparation was calculated. Descriptive statistics determined the mean $\pm S D$ of the mean neurite length from multiple cell preparations $(11,20)$. The data were analyzed by two-tailed paired $t$-test to determine significance. $P<0.05$ was set as statistically significant value.

\section{STATEMENT OF FINANCIAL SUPPORT}

This study was funded by grant UL1 RR 025005 (to A.M.) from the National Center for Research Resources (NCRR), Bethesda, MD, a component of the National Institutes of Health (NIH) and the NIH Roadmap for Medical Research; the Cobey Endowment (Baltimore, MD; to C.B.); the Munro Fund (Baltimore, MD; to C.B.); and NIH grant R01AA016398 (Bethesda, MD; to C.B.).

The contents are solely the responsibility of the authors and do not necessarily represent the official view of NCRR or $\mathrm{NIH}$.

Disclosure: A.M. received 1\% salary support from Sage Products (Carey, IL) from 1 July 2011 to 30 June 2012.

\section{REFERENCES}

1. Climo MW, Sepkowitz KA, Zuccotti G, et al. The effect of daily bathing with chlorhexidine on the acquisition of methicillin-resistant Staphylococcus aureus, vancomycin-resistant Enterococcus, and healthcare-associated bloodstream infections: results of a quasi-experimental multicenter trial. Crit Care Med 2009;37:1858-65.

2. O'Horo JC, Silva GL, Munoz-Price LS, Safdar N. The efficacy of daily bathing with chlorhexidine for reducing healthcare-associated bloodstream infections: a meta-analysis. Infect Control Hosp Epidemiol 2012;33:257-67.

3. Milstone AM, Passaretti CL, Perl TM. Chlorhexidine: expanding the armamentarium for infection control and prevention. Clin Infect Dis 2008;46:274-81.

4. O'Grady NP, Alexander M, Burns LA, et al.; Healthcare Infection Control Practices Advisory Committee (HICPAC). Guidelines for the prevention of intravascular catheter-related infections. Clin Infect Dis 2011;52:e162-93.

5. Case DE. Chlorhexidine: attempts to detect percutaneous absorption in man. Proc Int Cong Chemother 1976;3:367-74. 
6. Wilson CM, Gray G, Read JS, et al. Tolerance and safety of different concentrations of chlorhexidine for peripartum vaginal and infant washes: HIVNET 025. J Acquir Immune Defic Syndr 2004;35:138-43.

7. Mullany LC, Darmstadt GL, Tielsch JM. Safety and impact of chlorhexidine antisepsis interventions for improving neonatal health in developing countries. Pediatr Infect Dis J 2006;25:665-75.

8. Curley A, Kimbrough RD, Hawk RE, Nathenson G, Finberg L. Dermal absorption of hexachlorophene in infants. Lancet 1971;2:296-7.

9. Kopelman AE. Cutaneous absorption of hexachlorophene in low-birthweight infants. J Pediatr 1973;82:972-5.

10. Tamma PD, Aucott SW, Milstone AM. Chlorhexidine use in the neonatal intensive care unit: results from a national survey. Infect Control Hosp Epidemiol 2010;31:846-9.

11. Bearer CF, Swick AR, O'Riordan MA, Cheng G. Ethanol inhibits L1-mediated neurite outgrowth in postnatal rat cerebellar granule cells. J Biol Chem 1999;274:13264-70.

12. Watanabe H, Yamazaki M, Miyazaki H, et al. Phospholipase D2 functions as a downstream signaling molecule of MAP kinase pathway in L1-stimulated neurite outgrowth of cerebellar granule neurons. J Neurochem 2004;89:142-51.

13. Komljenovic I, Marquardt D, Harroun TA, Sternin E. Location of chlorhexidine in DMPC model membranes: a neutron diffraction study. Chem Phys Lipids 2010;163:480-7.

14. Schmuck G, Schlüter G. An in vitro model for toxicological investigations of environmental neurotoxins in primary neuronal cell cultures. Toxicol Ind Health 1996;12:683-96.

15. Cowen J, Ellis SH, McAinsh J. Absorption of chlorhexidine from the intact skin of newborn infants. Arch Dis Child 1979;54:379-83.

16. Shuman RM, Leech RW, Alvord EC Jr. Neurotoxicity of hexachlorophene in the human: I. A clinicopathologic study of 248 children. Pediatrics 1974;54:689-95.

17. Tyrala EE, Hillman LS, Hillman RE, Dodson WE. Clinical pharmacology of hexachlorophene in newborn infants. J Pediatr 1977;91:481-6.

18. Chapman A, Aucott S, Gilmore M, et al. Absorption and tolerability of aqueous chlorhexidine gluconate used for skin antisepsis prior to catheter insertion in preterm neonates. J Perinatol 2013;33:768-71.

19. Nakai Y, Kamiguchi H. Migration of nerve growth cones requires detergent-resistant membranes in a spatially defined and substrate-dependent manner. J Cell Biol 2002;159:1097-108.

20. Tang N, Farah B, He M, et al. Ethanol causes the redistribution of L1 cell adhesion molecule in lipid rafts. J Neurochem 2011;119:859-67.

21. Dolganiuc A, Bakis G, Kodys K, Mandrekar P, Szabo G. Acute ethanol treatment modulates Toll-like receptor-4 association with lipid rafts. Alcohol Clin Exp Res 2006;30:76-85.

22. Littner Y, Tang N, He M, Bearer CF. L1 cell adhesion molecule signaling is inhibited by ethanol in vivo. Alcohol Clin Exp Res 2013;37:383-9.
23. Ghare S, Patil M, Hote P, et al. Ethanol inhibits lipid raft-mediated TCR signaling and IL-2 expression: potential mechanism of alcohol-induced immune suppression. Alcohol Clin Exp Res 2011;35:1435-44.

24. Blanco AM, Perez-Arago A, Fernandez-Lizarbe S, Guerri C. Ethanol mimics ligand-mediated activation and endocytosis of IL-1RI/ TLR4 receptors via lipid rafts caveolae in astroglial cells. J Neurochem 2008;106:625-39.

25. Szabo G, Dolganiuc A, Dai Q, Pruett SB. TLR4, ethanol, and lipid rafts: a new mechanism of ethanol action with implications for other receptormediated effects. J Immunol 2007;178:1243-9.

26. Babich H, Wurzburger BJ, Rubin YL, Sinensky MC, Blau L. An in vitro study on the cytotoxicity of chlorhexidine digluconate to human gingival cells. Cell Biol Toxicol 1995;11:79-88.

27. Lessa FC, Aranha AM, Nogueira I, Giro EM, Hebling J, Costa CA. Toxicity of chlorhexidine on odontoblast-like cells. J Appl Oral Sci 2010;18:50-8.

28. Chang YC, Huang FM, Tai KW, Chou MY. The effect of sodium hypochlorite and chlorhexidine on cultured human periodontal ligament cells. Oral Surg Oral Med Oral Pathol Oral Radiol Endod 2001;92:446-50.

29. de Souza LB, de Aquino SG, de Souza PP, Hebling J, Costa CA. Cytotoxic effects of different concentrations of chlorhexidine. Am J Dent 2007;20:400-4.

30. Goldschmidt P, Cogen R, Taubman S. Cytopathologic effects of chlorhexidine on human cells. J Periodontol 1977;48:212-5.

31. Doan L, Piskoun B, Rosenberg AD, Blanck TJ, Phillips MS, Xu F. In vitro antiseptic effects on viability of neuronal and Schwann cells. Reg Anesth Pain Med 2012;37:131-8.

32. Tripier MF, Bérard M, Toga M, Martin-Bouyer G, Le Breton R, Garat J. Hexachlorophene and the central nervous system. Toxic effects in mice and baboons. Acta Neuropathol 1981;53:65-74.

33. Gongwer LE, Hubben K, Lenkiewicz RS, Hart ER, Cockrell BY. The effects of daily bathing of neonatal rhesus monkeys with an antimicrobial skin cleanser containing chlorhexidine gluconate. Toxicol Appl Pharmacol 1980;52:255-61.

34. Kronstein R, Seebach J, Grossklaus S, et al. Caveolin-1 opens endothelial cell junctions by targeting catenins. Cardiovasc Res 2012;93:130-40.

35. Wennberg RP. The blood-brain barrier and bilirubin encephalopathy. Cell Mol Neurobiol 2000;20:97-109.

36. Liebner S, Czupalla CJ, Wolburg H. Current concepts of blood-brain barrier development. Int J Dev Biol 2011;55:467-76.

37. Fransen E, D’Hooge R, Van Camp G, et al. L1 knockout mice show dilated ventricles, vermis hypoplasia and impaired exploration patterns. Hum Mol Genet 1998;7:999-1009.

38. Arifeen SE, Mullany LC, Shah R, et al. The effect of cord cleansing with chlorhexidine on neonatal mortality in rural Bangladesh: a communitybased, cluster-randomised trial. Lancet 2012;379:1022-8. 